\title{
Color Phenomena Associated With Energy Transfer in Afterglows and Atomic Flames
}

\author{
Arnold M. Bass and H. P. Broida
}

(April 10, 1963)

\begin{abstract}
Reactions involving reactive species produced in electric discharges are frequently characterized by the emission of visible light of many different colors. Some typical afterglows and atomic flames have been photographed, and the observed colors (or spectral distributions) are discussed with regard to the reactions from which they arise. Laboratory studies of this sort are helpful for the understanding of the energy transfer processes which occur in flames, in electrical discharges, and in the upper atmosphere.
\end{abstract}

\section{Introduction}

Brightly colored afterglows from electric discharges have provided a source of laboratory demonstrations and wonder for nearly 80 years. In 1884 Warburg $[1]^{1}$ noticed that, in a tube of nitrogen at low pressure which was subjected to an electric discharge, glows persisted for a long time after the exciting voltage was removed. Since the beginning of this century, afterglows in nitrogen [2] and oxygen [3] have been investigated extensively. Most of the phenomena associated with these afterglows are caused by reactions of atomic species [4]. It also has been found that under some conditions, in products of electric discharges condensed as solids at very low temperatures, there is an "afterglow" from the solid $[5,6]$.

When dissociation products from an electric discharge through gases at low pressure $(0.01$ to 100 $\mathrm{mm} \mathrm{Hg}$ ) are mixed with suitably reacting gases or vapors, bright regions known as atomic flames are observed [7]. In addition to the visible light which is observed and discussed below, there is also ultraviolet and infrared emission. Spectra of flames obtained on mixing hydrocarbons with atomic oxygen $[8,9]$ have been used as a method to help in the understanding of reaction zones in combustion processes. Emission spectra of brilliant glows obtained at the point of mixing of certain organic compounds with atomic nitrogen have been studied $[10,11]$ and used to obtain information about the reactions [12, 13] taking place. There is little emission from reactions taking place with hydrogen atoms $[7,8]$ but weak flames are observed from mixing ozone with hydrogen atoms, and much brighter flames from ozone mixed with both hydrogen and nitrogen atoms [14].

\footnotetext{
1 Figures in brackets indicate the literature references at the end of this paper.
}

Very few studies have been made of glows which occur in short times after the discharge. However some observations have been made as part of wind tunnel visualization efforts [15].

Previous attempts to obtain color photographs of these phenomena have met with only partial success. However, recent developments in photographic techniques and color film, as well as improved control of the afterglow and flame systems have made possible the satisfactory photographic recording of these glows. A group of photographs of characteristic glows and flames has been assembled in figures 2 through 9, and 11 through 24; figures 1 and 10 show the apparatus used for the excitation of the glows.

\section{Experimental Procedure}

Afterglows and atomic flames were photographed in the apparatus shown in figure 1. High purity gases from cylinders were admitted to the discharge region by means of control valves visible near the top of the picture. An electrodeless discharge was maintained in a quartz tube of $10 \mathrm{~mm}$ i.d. by means of a microwave cavity operated at $2450 \mathrm{Mc} / \mathrm{s}$ with a maximum input power of $125 \mathrm{w}$. With this arrangement, glows could be observed at pressures between 0.1 and $100 \mathrm{~mm} \mathrm{Hg}$. The brightest glows occurred at pressures between 1 and $10 \mathrm{~mm} \mathrm{Hg}$. Two different gases could be separately admitted and mixed before the discharge. A side tube in the cylindrical chamber $(9.5 \mathrm{~cm}$ diameter) allowed the mixing of another gas downstream from the discharge. Another inlet tube allowed pressure measurements to be made with an aneroid type, direct reading manometer. A pumping line $(2.5 \mathrm{~cm}$ diameter) was connected to a high speed, mechanical vacuum pump. 
In order to observe very short time phenomena the apparatus shown in figure 10 was used. In this apparatus, which was made of Pyrex glass, the electric discharge $(2450 \mathrm{Mc} / \mathrm{s})$ occurred in a converging-diverging (de Laval) nozzle with a throat of about $2 \mathrm{~mm}$ diam and an exit of $6 \mathrm{~mm}$. The gases were emptied into a $9 \mathrm{~cm}$ diam chamber, 100 cm long. A vacuum pump with a capacity of 500 liters/sec was used. Cleanliness of the apparatus and of the gases were essential for many of the phenomena which are pictured in this paper.

The critical factor for the reproducible photography of these phenomena is the correct control of exposure time. This was achieved through the use of a Honeywell Pentax $3^{\circ} / 21^{\circ}$ exposure meter which has very high sensitivity for an acceptance angle of $3^{\circ}$. The narrow acceptance angle permits exposure readings from restricted regions of the flames and thus adjustments may readily be made for small changes in brightness. These photographs were made on Kodachrome II film (daylight type) rated at an exposure index of 32 . Exposure times were varied from $1 / 25$ sec to 30 sec. Changes of exposure time by as little as a factor of 2 made the difference between good and poor color reproduction. For the longer exposures attempts were made to take account of the reciprocity-law failure by the use of color correction filters as recommended by the film manufacturer. However, it was found that the best color reproduction was obtained without the use of filters.

\section{Discussion}

Two general methods have been used in the study of afterglows. In a static gas system after pulsing an electrical discharge, changes of color can be observed as function of time. Alternatively, the same phenomena can be observed in a flowing gas system as a function of distance downstream from the discharge. The observed phenomena are caused by various reactions of energetic species. Different color regions indicate different concentrations of atoms, molecules, and ions and the collision processes occurring between these species.

There are many known species in discharges in pure atomic and diatomic gases: atoms and diatomic molecules each in several electronic states, ions of atoms and molecules, electrons, and photons. Conditions in the discharge affect the relative concentrations of these species. Concentrations change as a function of time after the discharge with most of the more energetic species decreasing monotonically with time. However in some cases, the collision processes cause increases of certain species. In nitrogen at times a few milliseconds after the discharge, the number of ions [16] and of electronically excited molecules is increased [17], (see fig. 6). A very energetic $\mathrm{N}_{4}$ molecule has been postulated as the energy carrier in this case [18]. At times of tens of microseconds after a discharge in very pure helium, there is a large increase in the concentration of elec- tronically excited helium atoms and diatomic helium molecules [19], (see fig. 13). The details of the energy exchange mechanisms involved in these short-time afterglows are not yet understood.

Some collision processes occurring in afterglows have been carefully studied. For example, the long-time nitrogen afterglow is understood in terms of reactions of nitrogen atoms to form molecular nitrogen $[20]$ :

$$
\mathrm{N}\left({ }^{4} \mathrm{~S}\right)+\mathrm{N}\left({ }^{4} \mathrm{~S}\right)+\mathrm{M} \rightarrow \mathrm{N}_{2}\left({ }^{5} \Sigma_{g}^{+}\right)+\mathrm{M}
$$

$\mathrm{M}$ is any third body in the three body collision process. The electronically excited molecule of nitrogen, $\mathrm{N}_{2}\left({ }^{5} \Sigma_{\mathrm{g}}^{+}\right)$can undergo a collision to change its electronic state to the upper state of the first positive system of nitrogen, $\mathrm{N}_{2}\left(\mathrm{~B}^{3} \Pi_{\mathrm{g}}\right)$ :

$$
\mathrm{N}_{2}\left({ }^{5} \Sigma_{g}^{+}\right)+\mathrm{M} \rightarrow \mathrm{N}_{2}\left(\mathrm{~B}^{3} \Pi_{\mathrm{g}}\right)+\mathrm{M} .
$$

This is followed by radiation of a photon, $h \nu$ :

$$
\mathrm{N}_{2}\left(\mathrm{~B}^{3} \Pi_{\mathrm{g}}\right) \rightarrow \mathrm{N}_{2}\left(\mathrm{~A}^{3} \Sigma_{u}^{+}\right)+h \nu
$$

Because the energy available in reaction (1) is equal to the dissociation energy of nitrogen, $9.76 \mathrm{ev}$ (plus a small addition of kinetic energy of the colliding particles), the total energy of the $\mathrm{B}^{3} \Pi_{g}$ molecular nitrogen is limited to this amount. As a consequence, the twelfth vibrational level of the $\mathrm{B}^{3} \Pi_{g}$ state is the highest one that can be populated. The emission from reaction (3) is the First Positive system of $\mathrm{N}_{2}$ with a non-Boltzmann distribution of vibrational populations, characterized in the visible region by a maximum near $v^{\prime}=10$.

It is this particular emission of the First Positive system of $\mathrm{N}_{2}$ which gives the "straw-yellow" color of figures 2 and 11 to the Lewis-Rayleigh nitrogen afterglow. If the nitrogen is diluted with large amounts of a rare gas such as helium, the population distribution in the $\mathrm{N}_{2}\left(\mathrm{~B}^{3} \Pi_{\mathrm{g}}\right)$ state is changed [21] moving to maximum populations near $v^{\prime}=8$. This corresponds to a shift toward the red end of the spectrum and is observed visually as a change in color of the afterglow. The change in color can be seen by comparing figures 2 and 3 , and figures 11 and 12 .

Impurities in the discharge cause large changes in concentrations and in the kinds of species. Additions of small amounts of oxygen cause large changes in the colors of the afterglow because of reactions with oxygen atoms formed in the discharge. Oxygen atoms can react with nitrogen producing $\mathrm{NO}$ molecules in the upper state of the $\beta$ bands of $N O, B{ }^{2} \Pi$ :

$$
\mathrm{N}\left({ }^{4} \mathrm{~S}\right)+\mathrm{O}\left({ }^{3} \mathrm{P}\right)+\mathrm{M} \rightarrow \mathrm{NO}\left(\mathrm{B}^{2} \mathrm{I}\right)+\mathrm{M}
$$

followed by

$$
\mathrm{NO}\left(\mathrm{B}^{2} \mathrm{II}\right) \rightarrow \mathrm{NO}\left(\mathrm{X}^{2} \mathrm{\Pi}\right)+h_{\nu}
$$

where $h \nu$ represents radiation which is brightest in 
the blue region of the spectrum [3, 22], (fig 4). Nitrogen atoms react rapidly with the NO to make $\mathrm{N}_{2}$ and oxygen atoms:

$$
\mathrm{N}\left({ }^{4} \mathrm{~S}\right)+\mathrm{NO} \rightarrow \mathrm{N}_{2}+\mathrm{O}\left({ }^{3} \mathrm{P}\right)
$$

When sufficient oxygen is added all the nitrogen atoms are consumed in the reactions. In the absence of nitrogen atoms, NO reacts with oxygen atoms to give $\mathrm{NO}_{2}$ in an electronically excited state [23] and this is followed by the emission of a photon.

$$
\begin{aligned}
& \mathrm{NO}+\mathrm{O}\left({ }^{3} \mathrm{P}\right)+\mathrm{M} \rightarrow \mathrm{NO}_{2}^{*}+\mathrm{M} \\
& \mathrm{NO}_{2}^{*} \rightarrow \mathrm{NO}_{2}+h \nu .
\end{aligned}
$$

Reaction (8) causes the yellow green "air afterglow" shown in figure 5.

Bright "atomic flames" often can be seen when gases or vapors are added to the atoms produced in the discharge. For example the glow produced by reaction (8) is formed by adding $\mathrm{NO}$ in excess of the amount of nitrogen atoms to the afterglow of pure nitrogen. Thus the color, and the spectral emission, of figures 5 and 7 are the same. If hydrocarbon vapors are added to nitrogen, as in figures 8 and 22 , bright visible emission caused predominatly by $\mathrm{CN}$ is observed [10,11, 13]. Atomic oxygen mixed with hydrocarbons shows a completely different appearance (figs. 9 and 21) because the emission is due to $\mathrm{CH}$ and $\mathrm{C}_{2}[8,9]$.

To observe steady-state afterglows at very short times after a discharge, it has been necessary to use supersonic flows from a discharge in a de Laval nozzle [15, 19]. At such high gas velocities, or rather in such short times, there is very little mixing of gases as illustrated in figure 14. However it is possible to observe some very efficient collision processes with metastable helium triplet state atoms. Energy exchange collisions with neon cause excitation of many electronic states of neon (figs. 15 and 16). Oxygen and nitrogen are ionized as well as electronically excited by collisions with metastable helium atoms, by what is known as the Penning process [24]:

$$
\begin{aligned}
& \text { He }\left(2{ }^{3} \mathrm{~S}\right)+\mathrm{N}_{2} \rightarrow \mathrm{N}_{2}^{+}+\mathrm{He}\left({ }^{1}{ }^{1} \mathrm{~S}\right)+e \\
& \mathrm{He}\left(2{ }^{3} \mathrm{~S}\right)+\mathrm{O}_{2} \rightarrow \mathrm{O}_{2}^{+}+\mathrm{He}\left({ }^{1}{ }^{1} \mathrm{~S}\right)+e
\end{aligned}
$$

Some dissociation of molecules also occurs since emission of atomic oxygen has been observed [19]. In figures 17,18 , and 19 the zones in the flames in which the various species are excited are clearly distinguishable from the colors: atomic and molecular helium is pink; $\mathrm{N}_{2}^{+}$is blue; $\mathrm{O}_{2}^{+}$and $\mathrm{O}$ are green. The diamond-shaped regions in which the different species appear are characteristic of shock fronts in the supersonic flow regime.

\section{References}

[1] E. Warburg, Arch. de Gen. (3) 12, 504 (1884).

[2] R. E. Jennings, and J. W. Linnett, Quart. Rev. 12, 116 (1958).

[3] F. Kaufman, in Progress in Reaction Kineties 1, pp 1 (Pergamon Press, N.Y. 1961).

[4] K. R. Jennings, Quart. Rev. 15, 237 (1961).

[5] C. M. Herzfeld and A. M. Bass, Sci. Amer. 90 (Mar., $1957)$.

[6] H. P. Broida, Endeavour 1\%, 208 (1958).

[7] A. G. Gaydon, The Spectroscopy of Flames, pp 39-42, 158, 252 (Chapman and Hall, 1957).

[8] A. G. Gaydon and H. G. Wolfhard, Proc. Roy. Soc. A213, 366 (1952)

[9] R. E. Ferguson and H. P. Broida, 5th Symposium on Combustion p. 754 (Reinhold Publ. Co., N.Y. 1955).

[10] N. H. Kiess and H. P. Broida, 7th Symposium on Combustion p. 207, (Butterworths Scientific Publications, London 1959).

[11] K. R. Jennings and J. W. Linnett, Trans. Faraday Soc. 56, $1737(1960)$.

[12] H. G. V. Evans and C. A. Winkler, Can. J. Chem. 34, 1271 (1956).

[13] H. E. Radford and H. P. Broida, J. Chem. Phys. 38, 644 (1963).

[14] D. Garvin and H. P. Broida, 9th Symposium on Combustion (Academic Press, N.Y. 1963).

[15] W. B. Kunkel and F. C. Hurlbut, J. App. Phys. 28, 827 (1957).

[16] I. Tanaka and H. P. Broida, J. Chem. Phys. 36, 236 (1962)

[17] G. E. Beale and H. P. Broida, J. Chem. Phys. 31, 1030 (1959).

[18] A. B. Prag and K. C. Clark, J. Chem. Phys. (to be published).

[19] A. L. Schmeltekopf, Jr. and H. P. Broida, J. Chem. Phys. (to be published).

[20] P. K. Carroll, J. Chem. Phys. 37, 805 (1962).

[21] U. H. Kurzweg and H. P. Broida, J. Molecular Spect. 3, 388 (1959).

[22] U. H. Kurzweg, A. M. Bass, and H. P. Broida, J. Molecular Spect. 1, 184 (1957).

[23] H. P. Broida, H. I. Schiff, and T. M. Sugden, Trans. Faraday Soc. 5\%, 259 (1961).

[24] E. E. Benton, E. E. Ferguson, F. A. Matsen, and W. W. Robertson, Phys. Rev. 128, 206 (1962).

(Paper 67A4-228)

(See figures 1 to 24 on the following pages.) 


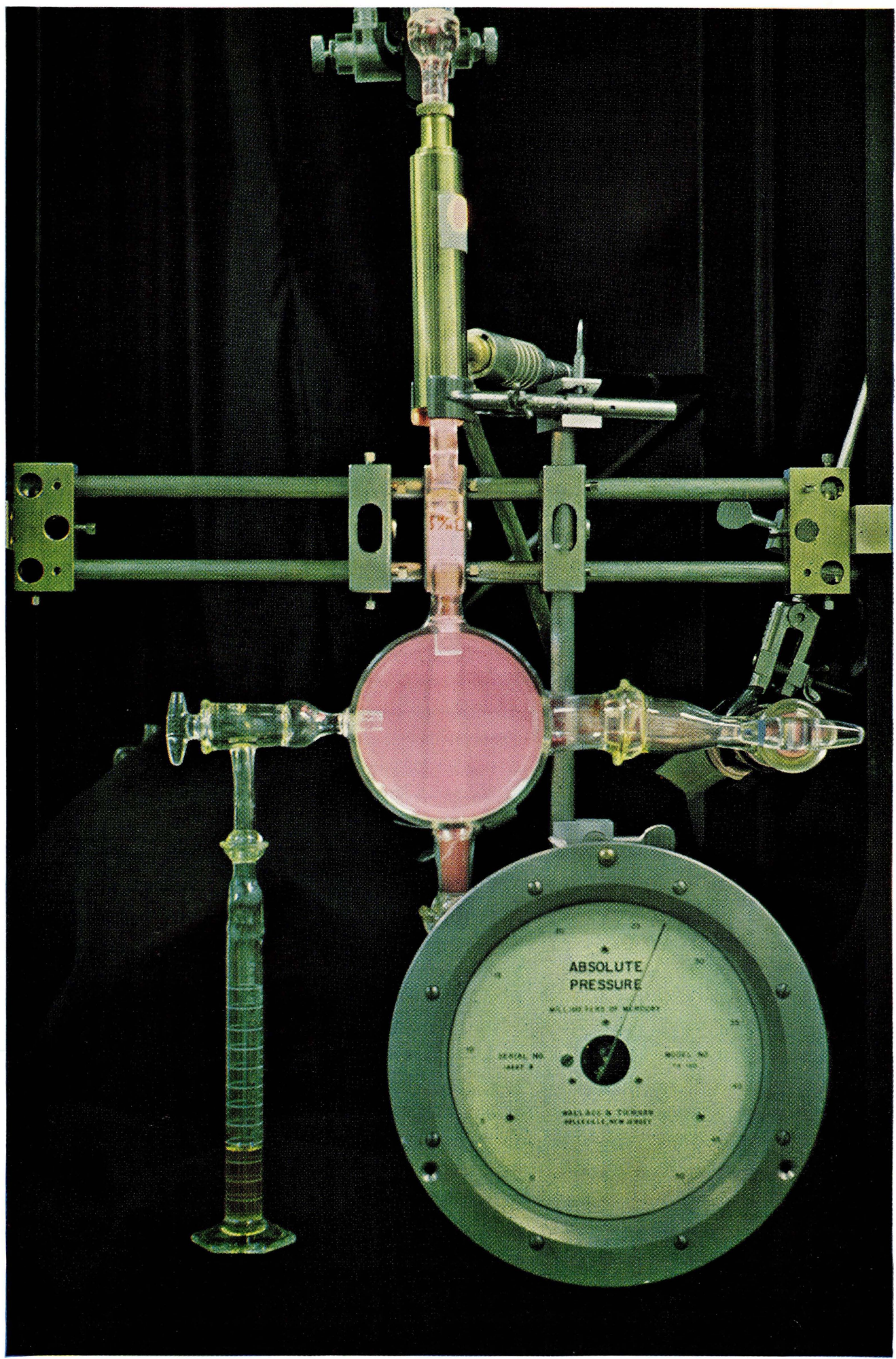

Figure 1. Apparatus for producing afterglows and atomic flames. The pink glow in the cylindrical vessel is a nitrogen afterglow in an excess of helium at a pressure of $27 \mathrm{~mm} \mathrm{Hg}$. 


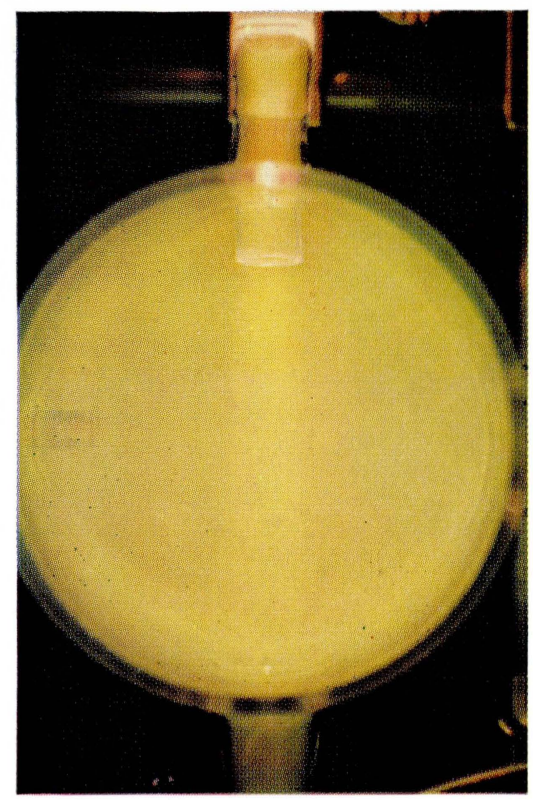

2

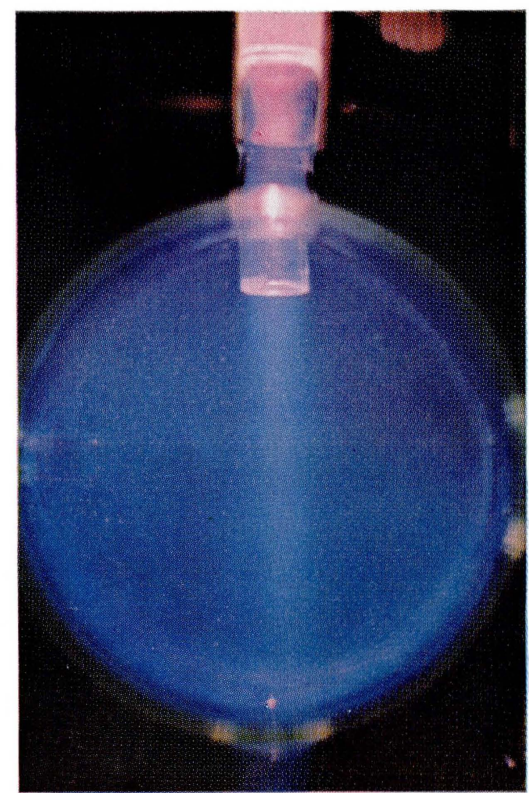

4

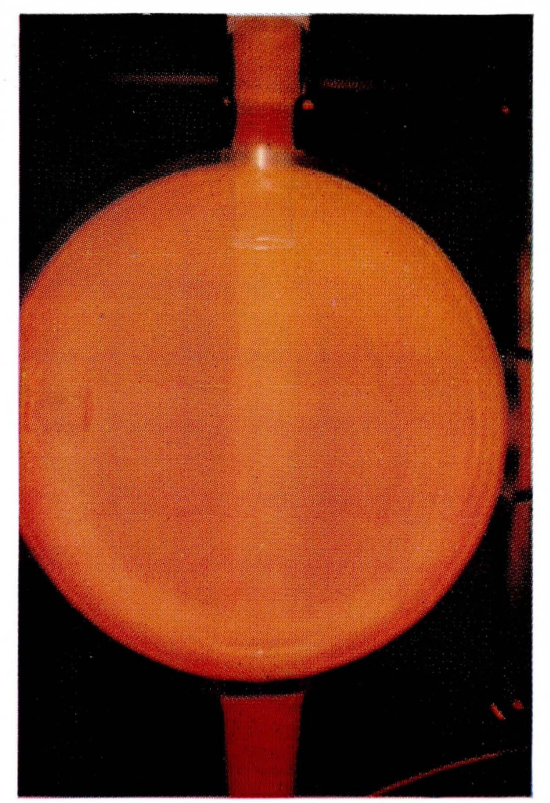

3

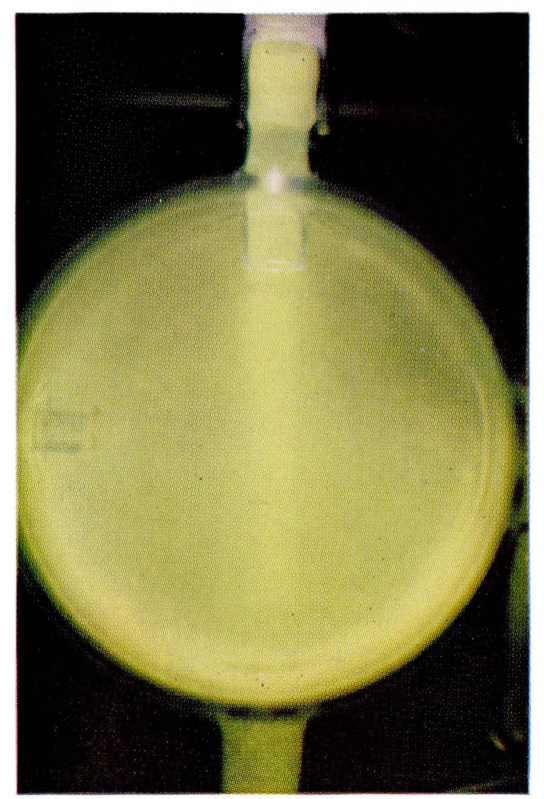

5

\section{Afterglows from Discharges Through Nitrogen}

Figure 2. Pure nitrogen at $4 \mathrm{~mm} \mathrm{Hg}$, pressure showing the typical Lewis-Rayleigh afterglow. Figure 3. Same amount of nitrogen in large excess of helium at $50 \mathrm{~mm} \mathrm{Hg}$.

Figure 4. Approximately 1 percent $\mathrm{O}_{2}$ added to the nitrogen of figure 2 .

Figure 5. Approximately 3 percent $\mathrm{O}_{2}$ added to the nitrogen, showing the "air-afterglow." 


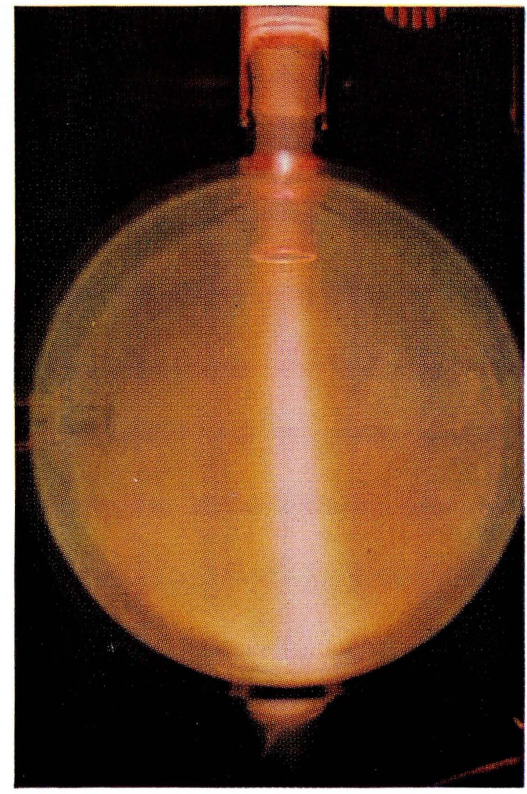

6

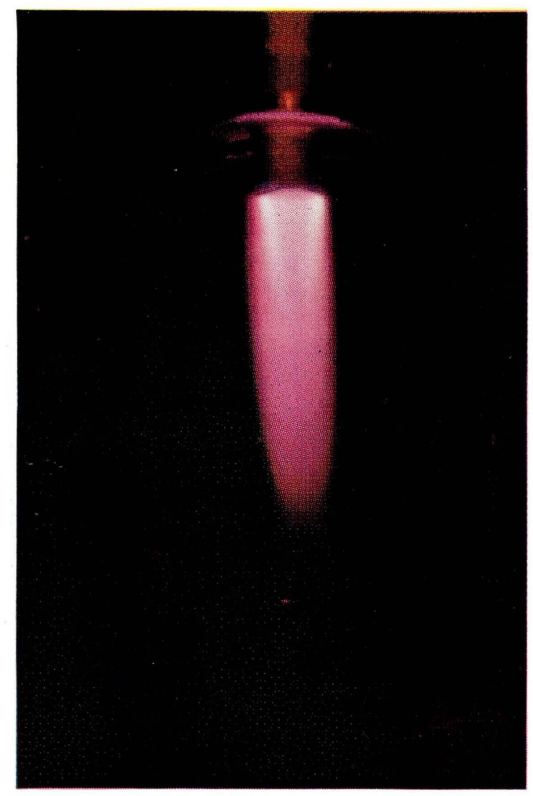

8

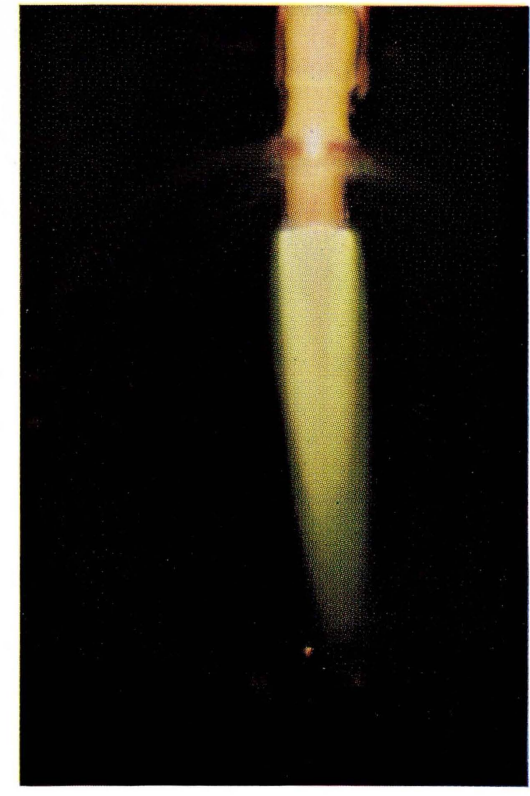

7

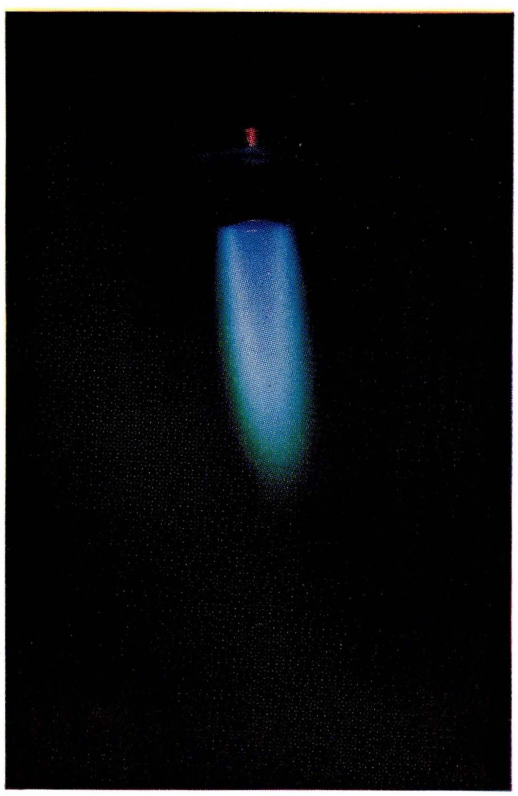

9

Afterglows from Discharges Through Nitrogen-Continued

FIGURE 6. Short-duration, pink "auroral" afterglow surrounded by the Lewis-Rayleigh afterglow at $4 \mathrm{~mm} \mathrm{Hg}$.

\section{Atomic Flames}

Figure 7. Nitrogen atoms with added nitric oxide (NO).

FIGURE 8. Nitrogen atoms with added methylene chloride $\left(\mathrm{CH}_{2} \mathrm{Cl}_{2}\right)$.

Figure 9. Oxygen atoms with added acetylene $\left(\mathrm{C}_{2} \mathrm{H}_{2}\right)$. 


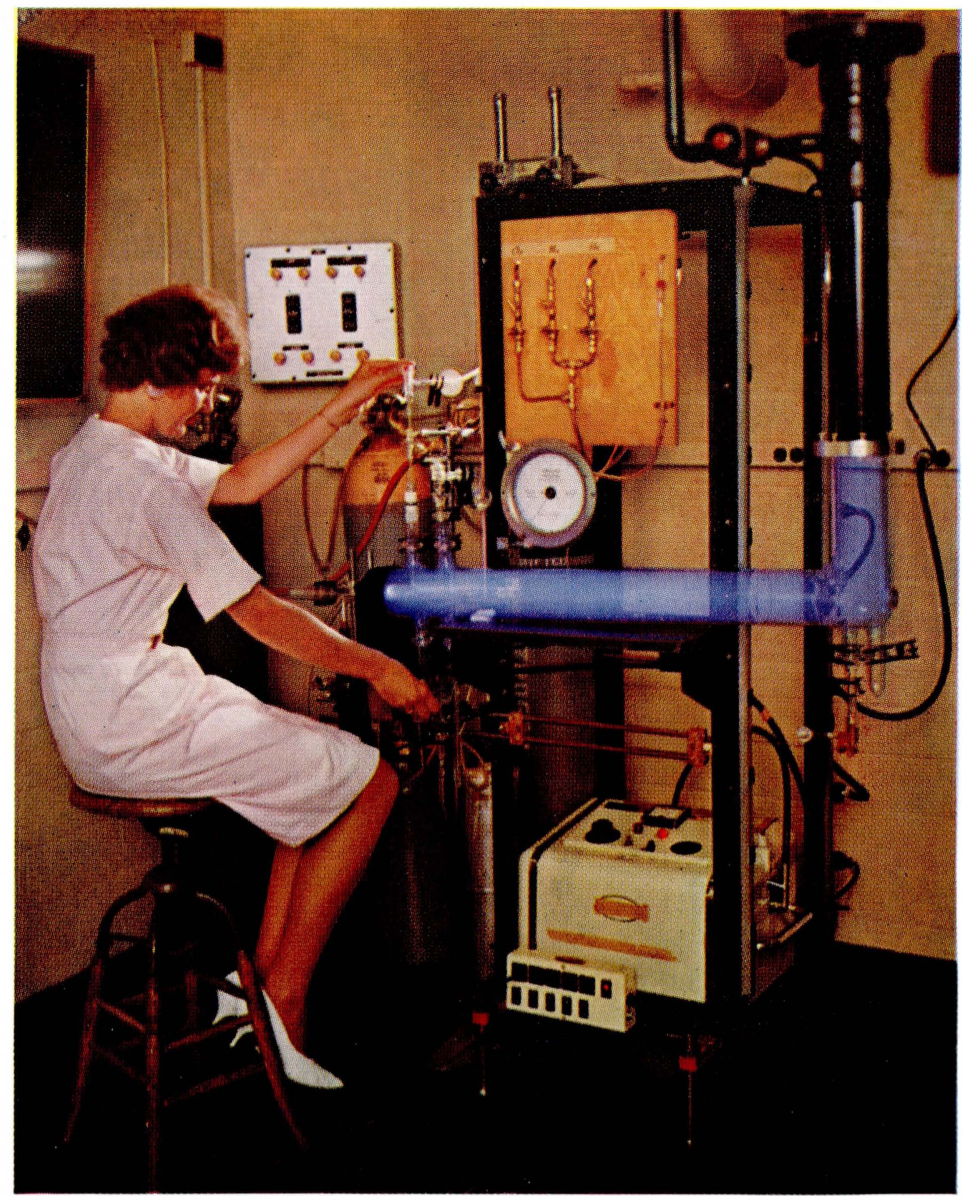

10

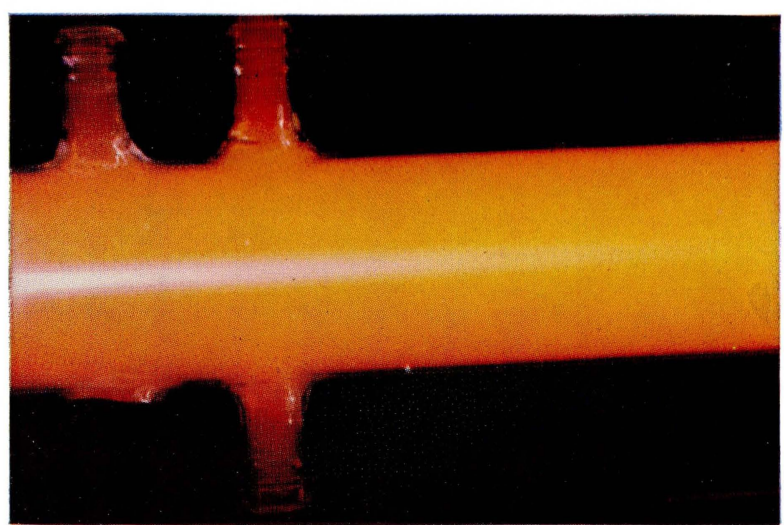

11

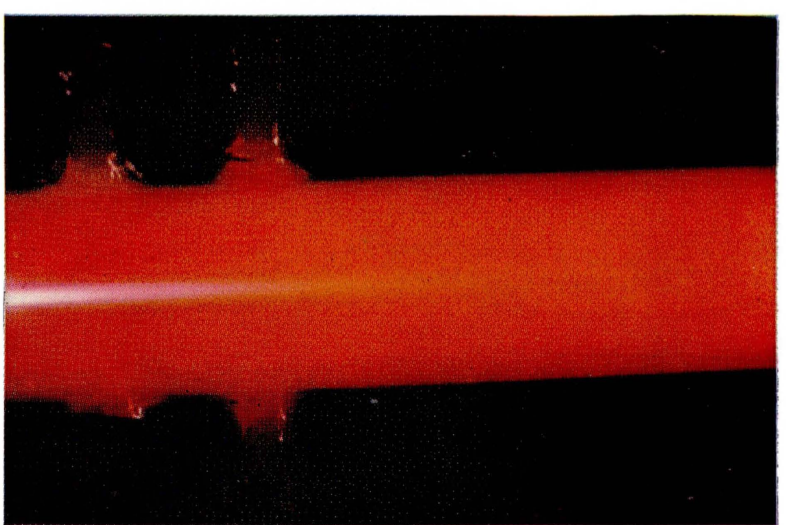

12

Atomic Flames-Continued

Figure 10. Astrojet apparatus for producing helium afterglows and flames.

Afterglows from Discharges Through Nitrogen in the Astrojet

Figure 11. Pure nitrogen.

Figure 12. Nitrogen with large excess of helium. 


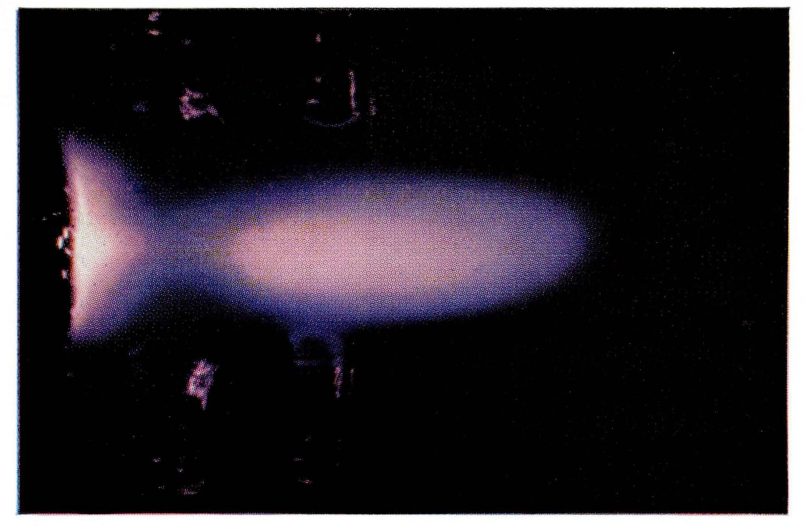

13

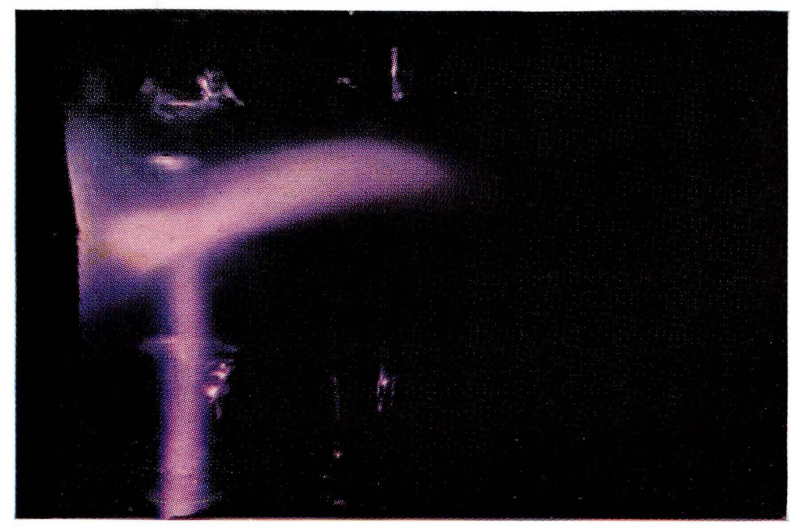

14

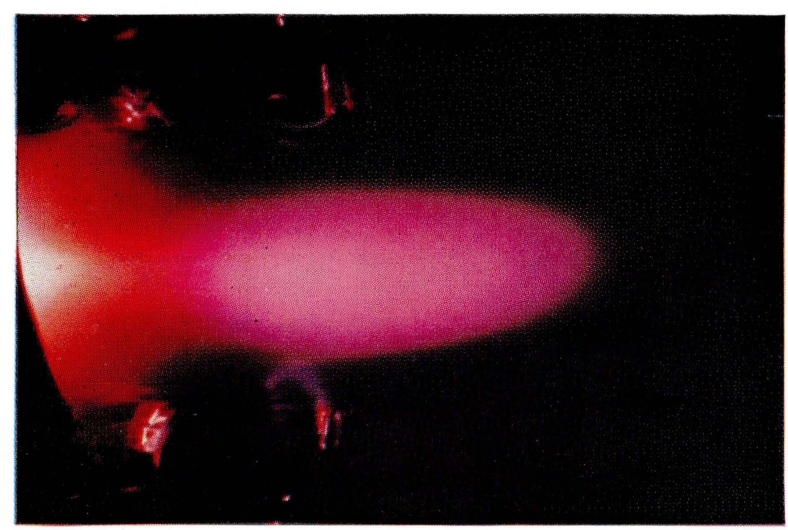

15

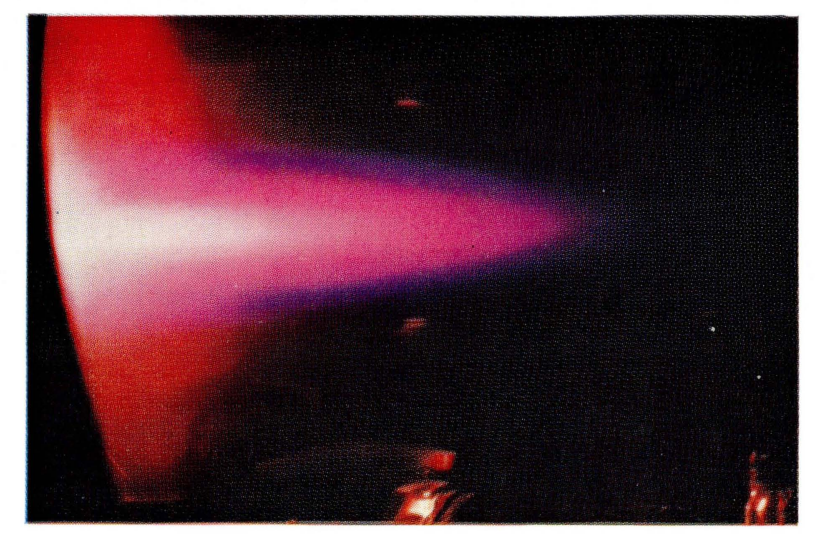

16

Short-Duration Glows from Discharges Through Helium in a deLaval Nozzle

Figure 13. Pure helium afterglow at $1.4 \mathrm{~mm} \mathrm{Hg.}$

Figure 14. Intersection of two high-velocity gas streams each showing the pure helium afterglow.

Figure 15. Same conditions as $13(1.4 \mathrm{~mm} \mathrm{Hg})$ with the addition of less than 0.01 percent neon downstream from the discharge.

Figure 16. Same mixture as 15 at $10 \mathrm{~mm} \mathrm{Hg}$. 


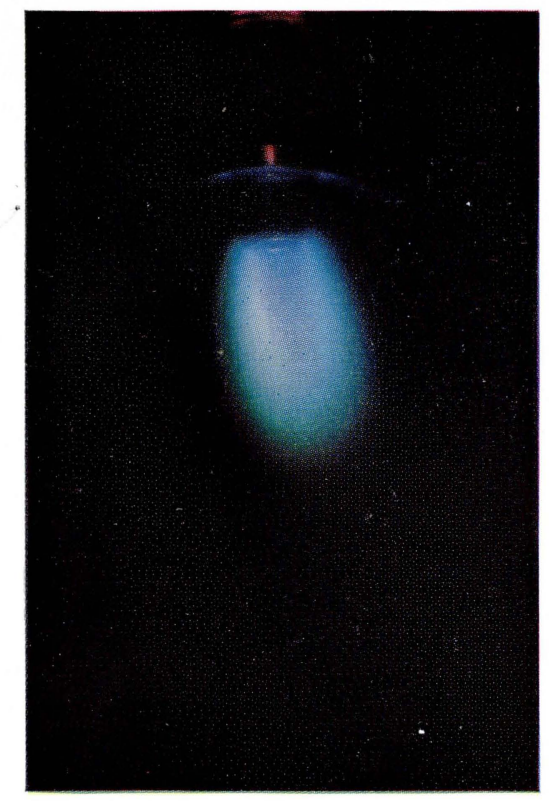

21

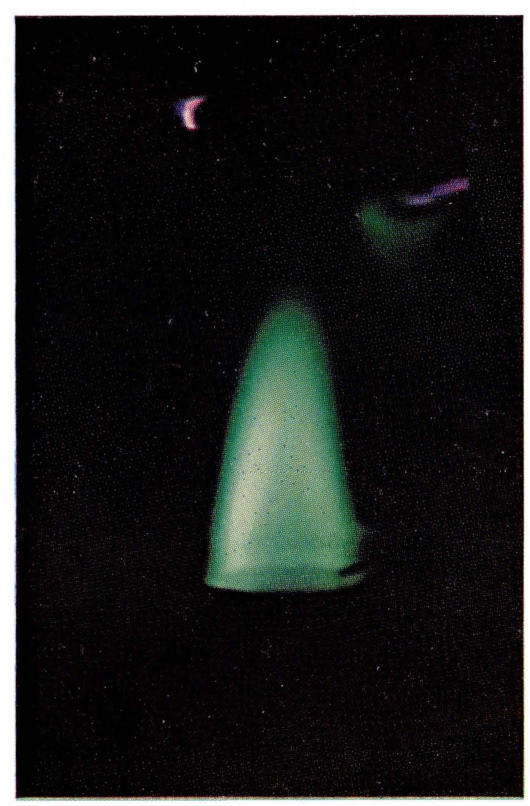

23

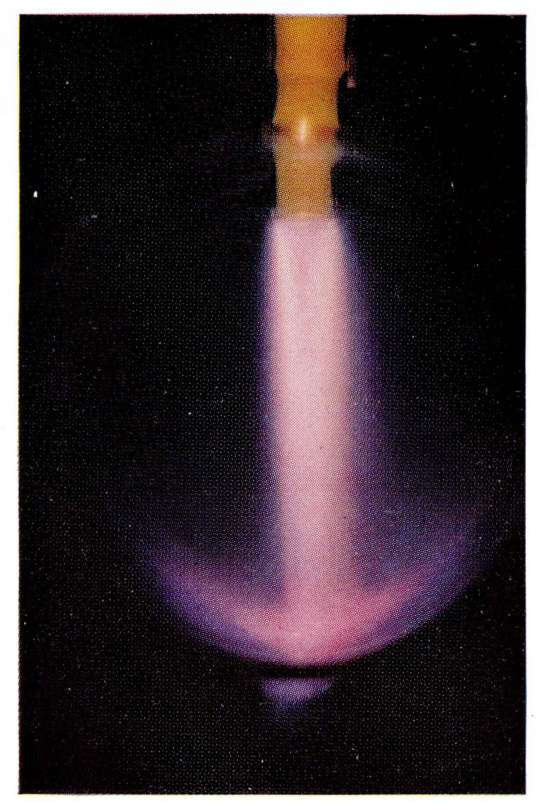

22

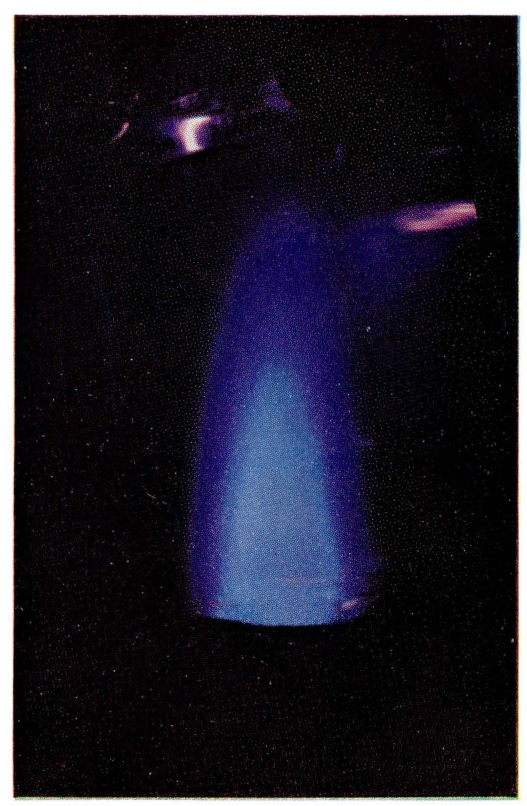

24

\section{Flames}

Figure 21. Atomic oxygen with added acetylene $\left(\mathrm{C}_{2} \mathrm{H}_{2}\right)$.

Figure 22. Atomic nitrogen with added methylene chlorine $\left(\mathrm{CH}_{2} \mathrm{Cl}_{2}\right)$.

Figure 23. Metastable helium with added oxygen.

Figure 24. Metastable helium with added nitrogen. 


\section{Publications of the National Bureau of Standards*}

\section{Selected Abstracts}

Effect of molecular weight on viscoelastic properties of poly mers as predicted by a molecular theory, $H$. Oser and R. S. Marvin, J. Research NBS 6\%B (Math. \& Math. Phys.), No. 2, 87 (Apr.-June 1963).

Calculations have been made covering the predictions of a model representing the viscoelastic behavior of rubberlike polymers for molecular weights greater than $M_{c}, M_{c}$ being the lower limit of the range in which the viscosity is proportional to $M^{3.4}$. A pronounced difference in the character of $G^{\prime \prime}$ is predicted for polymers with molecular weights between five and ten times $M_{c}$ as compared with those whose molecular weights are outside this range.

The specific heat of saturated liquid para-hydrogen from 15 to $32^{\circ} \mathbf{K}$, B. A. Younglove and D. E. Diller, Cryogenıcs 2 , No. 5, 1-5 (Sept. 1962).

The specific heat of saturated liquid para-hydrogen $C_{\sigma}$ has been measured as part of a programme for determining the thermodynamic properties of para-hydrogen at high densities and low temperatures. Thermodynamic properties of the compressed liquid have been computed using $C_{\sigma}$ as the baseline. The specific heat of argon has been measured for comparison with that of Flubacher, Leadbetter, and Morrison. Also the $C_{\sigma}$ of para-hydrogen has been measured by others, which provides an additional comparison. The results obtained in this work serve to evaluate the accuracy that may be expected in future measurements of compressed fluids with this apparatus.

Thermal reactions of isobutyl radicals, W. M. Jackson, J. R McNesby and B. deB. Darwent, J. Chem. Phys. 37, No. 10, 2256-2260 (Nov. 1962).

Deuterium labeled isobutane $\left(\mathrm{CH}_{3}\right)_{3} \mathrm{CD}$ was pyrolyzed to generate $\left(\mathrm{CH}_{3}\right)_{3} \mathrm{C}$ and $\mathrm{CH}_{2} \mathrm{CD}\left(\mathrm{CH}_{3}\right)_{2}$ radicals. The competition between reactions (5) and (6) was studied by isotopic analysis of the hydrogen, methane and isobutene fractions.

$$
\begin{aligned}
& \mathrm{CH}_{2} \mathrm{CD}\left(\mathrm{CH}_{3}\right)_{2} \rightarrow \mathrm{CH}_{2}=\mathrm{C}\left(\mathrm{CH}_{3}\right)_{2}+\mathrm{D} \\
& \mathrm{CH}_{2} \mathrm{CD}\left(\mathrm{CH}_{3}\right)_{2} \rightarrow \mathrm{CH}_{2}=\mathrm{CDCH}_{3}+\mathrm{CH}_{3}
\end{aligned}
$$

Reaction (5) was found to be of negligible importance relative to reaction (6) up to $540^{\circ} \mathrm{C}$ and it is concluded that previous estimates of $k 5 / k 6$ (in the non-deuterated species) are too high by at least an order of magnitude. The expulsion of molecular hydrogen by isobutyl or t-butyl does not occur in competition with other unimolecular reactions of these radicals.

Intramolecular rearrangements. V. Formation of ethylene in the photolysis of ethyl acetate from 4 to $500^{\circ} \mathrm{K}, \mathrm{P}$. Ausloos and R. E. Rebbert, J. Phys. Chem. 67, No. 1, 163-167 (Jan. 1963).

The formation of ethylene in the gas, liquid and solid phase photolysis of $\mathrm{CH}_{3} \mathrm{COOC}_{2} \mathrm{H}_{5}, \quad \mathrm{CH}_{3} \mathrm{COOCD}_{2} \mathrm{CD}_{2} \mathrm{H}$ and $\mathrm{CH}_{3} \mathrm{COOC}_{2} \mathrm{D}_{5}$ has been investigated at various wavelengths and temperatures. The intramolecular isotope effect increases with a decrease in temperature in both the gas and liquid phase photolysis. In the liquid phase an activation energy difference of $1 \mathrm{kcal} / \mathrm{mole}$ was obtained for $\mathrm{D}$ and $\mathrm{H}$-atom transfer in the photolysis of $\mathrm{CH}_{3} \mathrm{COOCD}_{2} \mathrm{CD}_{2} \mathrm{H}$. A variation in wavelength influences the formation of ethylene in the gas and solid phases but does not affect the intra and inter molecular isotope effects in the liquid phase. A comparison of the product yields in the mercury sensitized decomposition with those obtained in the direct photolysis, as well as a study of the effect of biacetyl on the ethylene yield, indicates that the formation of ethylene by an intramolecular rearrangement of the ester molecule excited to an upper triplet state cannot be ruled out.
Microwave studies of butadiene derivatives. I. Spectrum of fluoroprene, D. R. Lide, Jr., J. Chem. Phys. 3\%, No. 9, 2074-2079 (Nov. 1962).

The microwave spectrum of fluoroprene $\left(\mathrm{CH}_{2}=\mathrm{CHCF}=\mathrm{CH}_{2}\right)$ has been studied in the $8-35 \mathrm{kMc}$ region. The molecule is shown to have a planar trans configuration with ground-state rotational constants $a=10000.26, b=4264.35, c=2989.21 \mathrm{Mc}$. The spectra of five excited vibrational states, including the first three excited torsional states, have been analyzed in detail. Relative intensity measurements give a torsional frequency of $156 \pm 9 \mathrm{~cm}^{-1}$ with no detectable anharmonicity. Negative inertial defects are observed in the excited torsional states; this is explained by a simple model of the torsional oscillation. The dipole moment in the ground state has a magnitude of $1.417 \pm 0.010 \mathrm{D}$ and makes an angle of $10^{\circ}-15^{\circ}$ with the $\mathrm{C}-\mathrm{F}$ bond. Possible forms of the torsional potential function which are consistent with the experimental results are discussed. It is suggested that a function which allows for a non-planar isomer in butadiene-type molecules (so far unobserved) gives a reasonable explanation of all the present data.

Critical opalescence of polystyrene solutions, D. MeIntyre, A. Wims, and M. S. Green, J. Chem. Phys. 3\%, No. 12, 3019-3020 (Dec. 1962).

An experimental study of the critical opalescence of polystyrene solutions was made. The angular variation of intensity and the temperature dependence of intensity indicates some differences from the Debye and Ornsteim-Zernicke theory.

Refraction and dispersion of synthetic sapphire, I. H. Maltison J. Opt. Soc. Am. 52, No. 12, 137\%-1379 (Dec. 1962).

The refractive indices of synthetic sapphire were measured at selected wavelengths and the values of index range from 1.834 at $0.265 \mu$ in the ultraviolet to 1.586 at $5.58 \mu$ in the infrared. A three-term Sellmeier dispersion equation of the form

$$
n^{2}-1=\sum_{i} \frac{A_{i} \lambda^{2}}{\lambda^{2}-\lambda_{i}^{2}}
$$

was fitted to the experimental data. Dispersive quantities were computed which estimate the optical performance to be expected from sapphire.

Thermophysical properties of zirconium hydrides, R. L. Beck and T. B. Douglas, Trans. Am. Soc. Metals 55, 1075-1076 (1962).

Attention is called to the emphasis by metallurgists and physical chemists of different sets of properties of metal hydrides, but it is pointed out that almost all properties indicate and are influenced by the phase-field boundaries. The author (of the paper discussed) shows commendable caution in interpreting data in terms of these boundaries. More two-way approach to immobile equilibria is recommended, and the writer cites some of his own experience. One heat capacity reported, while not precise, agrees with a recent correlation by the writer of the Zr-H system. The writer criticizes the implication that two coexistent phases have the same heat capacity. He points out that an ideal heat-capacity curve has a discontinuity on entering a twophase field and that for a given simple composition the heat capacity in the latter field is always greater than in an adjacent one-phase field.

Nuclear magnetic resonance of $\mathrm{Ni}^{61}$ in dilute alloys of nickel in cobalt, R. L. Streever, L. H. Bennett, R. C. LaForce, and G. F. Day, Phys, Rev. 128, No. 4, 1632-1633 (Nov. 1962)

The nuclear magnetic resonance of $\mathrm{Ni}^{61}$ has been observed in $1 \% \mathrm{Ni}^{61}-99 \% \mathrm{Co}$ and $2 \% \mathrm{Ni}^{61}-98 \%$ Co alloys. The 
esonance frequency is $70.4 \mathrm{Mc} / \mathrm{sec}$ at room temperature and $71.7 \mathrm{Mc} / \mathrm{sec}$ at $77^{\circ} \mathrm{K}$. The hyperfine field at nickel in cobalt is about two and a half times its value in pure nickel, implying a nearly proportional increase in the local magnetic moment.

The bound-free absorption coefficient of the hydrogen negative ion, S. Geltman, Astrophys. J. 136, No. 3, 935-945 (Nov. 1962).

The bound-free absorption coefficient of $\mathrm{H}^{-}$is evaluated using a set of successively improved bound and free state wave functions. Better agreement with experiment and greater theoretical consistency are shown to result. The best theoretical result is tabulated for use in astrophysical applications.

Heats of formation of two isomers of difluorodiazine, G. T. Armstrong and S. Marantz, I. Chem. Phys. 38, No. 1 , 169-172 (.Jan. 1963).

The heats associated with the reaction

$$
\mathrm{N}_{2} \mathrm{~F}_{2}(\mathrm{~g})+\frac{8}{3} \mathrm{NH}_{3}(\mathrm{~g})=2 \mathrm{NH}_{4} \mathrm{~F}(\mathrm{c})+\frac{4}{3} \mathrm{~N}_{2}(\mathrm{~g})
$$

were observed for two mixtures containing the trans and the "active" isomeric forms of difluorodiazine $\left(\mathrm{N}_{2} \mathrm{~F}_{2}\right)$ in different proportions. From the observed heats of reaction of the two samples the heat of isomerization, $\triangle H_{298}^{\circ}$, of "active" to trans- $\mathrm{N}_{2} \mathrm{~F}_{2}$ was found to be $3.0 \mathrm{kcal}$ mole ${ }^{-1}$ with calculated standard error of $0.3 \mathrm{kcal} \mathrm{mole}-1$ based on four degrees of freedom. With the use of auxiliary data for $\mathrm{NH}_{3}$ and $\mathrm{NH}_{4} \mathrm{~F}$, the heats of formation $\triangle H f_{298}^{\circ}$ were determined to be +19.4 and +16.4 keal mole $^{-1}$ for the trans and the "active" isomers respectively. The bond energies in the two substances are discussed in terms of the possible molecular configurations.

Method for finding the density expansion of transport coefficients of gases, R. Zwanzig, Phys. Rev. 129, No. 1, 486-494 (Jan. 1, 1963).

This article presents a new method for finding the density expansion of certain transport coefficients of gases. These are the self-diffusion coefficient, and the momentum contributions to viscosity, thermal conductivity, etc. The method is to calculate the time-correlation function associated with the transport process. To lowest order in density, the results are identical with those found by Enskog's first order perturbation solution of the Boltzmann equation. The first density correction requires the solution of a certain three body problem. This problem is stated precisely, but is not solved.

$\gamma$-Irradiation of small molecules at 4 and $\boldsymbol{\gamma} \boldsymbol{\gamma}^{\circ} \mathbf{K}, \mathrm{R}$. E. Florin,

D. W. Brown, and L. A. Wall, J. Phys. Chem. 66, 2672-2676 (Dec. 1962).

The gamma irradiation of $\mathrm{CH}_{4}, \mathrm{CF}_{4}$ and $\mathrm{SiF}_{4}$ was investigated by electron spin resonance both at $4^{\circ} \mathrm{K}$ and $77^{\circ} \mathrm{K}$. The influence of inert matrices of Xe was also studied and found to be useful in trapping radical species, particularly at $77^{\circ} \mathrm{K}$. The electron spin resonance spectra for the radicals $\mathrm{CH}_{3}, \mathrm{CF}_{3}$ were profoundly altered by both temperature and presence of the matrix, whereas that for $\mathrm{SiF}_{3}$ was not. Spectra from several irradiated fluorocarbons are also reported.

Measuring plasma density of the magnetosphere, K. L. Bowles, Science 139, No. 3553, 389-391 (Feb. 1, 1963).

This note reports a brief review of the incoherent scatter technique for measuring electron density and temperate profiles in the magnetosphere. Examples of early data are given.

Complex formation between manganese (II), nickel (II), and zinc (II) ions and some symmetrically substituted ethylenediamines: The use of $\boldsymbol{E}_{r}$ and $\delta \boldsymbol{H}$ values in assessing inductive and steric effects, D. L. Leussing, Inorganic Chem. 2, No. $7 \%, 7 \%-82$ (1963).

Using the procedures of George and MeClure, $E_{r}$ and $\delta H_{\mathrm{N}}$ values have been calculated from the formation constants of manganese (II), nickel (II), and zinc (II) complexes with some symmetrically substituted ethylenediamines. It is shown that $C$-substitution by alkyl groups appreciably increases the $E_{r}$ values in the direction expected for an increase in the ligand nucleophilicity. $N$-substitution brings about an effect in the same direction but of smaller magnitude. The $\delta H_{\mathrm{Ni}}$ values are lower for the substituted ethylenediamines than for the unsubstituted ligand. It is possible to correlate the $\delta H_{\mathrm{Ni}}$ values with both the spectral band positions of the respective complexes and their activation energies for dissociation. The data indicate that the stabilities of nickel (ii) complexes are highly sensitive to steric influences. A comparison of the properties of the amine complexes of nickel (II) with those of mercaptide indicates that $d_{\pi}-p_{\pi}$ bonding between nickel (II) and sulfur is the cause for the unusually low stabilities of these latter complexes.

Calorimetric determination of half-cell entropy changes, J. M. Sherfey, J. Electrochem. Soc. 110, No. 3, 213-221 (Mar. 1963)

The reversible heat effects $(T \triangle S$ ) of half-cell processes have been measured in a twin calorimeter consisting of a Dewar flask divided into two halves by means of a vertical partition. Both compartments contain the same electrolyte and each has an electrode. A hole in the partition, covered by filter paper, permits the passage of electrolytic current between the compartments.

The total heat effect and the heat due to irreversible phenomena are measured separately for each compartment. The difference between these two gives the desired reversible heat. The half-cells studied include copper in acid copper sulfate, silver in acid silver perchlorate, and silver-silver chloride in various chloride solutions. The effect of "transport entropies" on these measurements is outlined. Presently accepted theories of the "irreversible" or "steady state" thermodynamics of electrolytic cells predict the equivalence of half-cell entropy data obtained by the present calorimetric method and data obtained from thermocell studies. This predicted agreement was not obtained in the case of the halfcell silver-silver perchlorate.

Hartree-Fock approximation of $\mathbf{C H}_{4}$ and $\mathbf{N H}_{4}^{+}$, M. Krauss, J. Chem. Phys. 38, No. 2, 564-565 (Jan. 15, 1963).

Molecular energies, which approach the Hartree-Fock limit, have been computed for the $\mathrm{CH}_{4}$ and $\mathrm{NH}_{4}^{+}$molecules at their equilibrium distances. These results verify the suitability of exponential quadratic functions as basis functions in molecular calculations.

Formation of decay of atoms and small free radicals at low temperatures, D. W. Brown, R. E. Florin and L. A. Wall, J. Phys. Chem. 66, 2602-2612 (Dec. 1962).

The maximum numbers of atoms that can be produced by exposing solid $\mathrm{H}_{2}, \mathrm{D}_{2}, \mathrm{~N}_{2}$, and $\mathrm{CH}_{4}$ to gamma radiation at $4.2^{\circ} \mathrm{K}$ were investigated using the electron spin resonance method. The limiting values expressed in mole percent were estimated to be $0.1 \% \mathrm{~N}$ atoms in $\mathrm{N}_{2} ; 0.2 \%$ each of $\mathrm{H}$ atoms and $\mathrm{CH}_{3}$ radicals in $\mathrm{CH}_{4}$; less than $0.008 \%$ D atoms in $\mathrm{D}_{2}$; and $0.0001 \% \mathrm{H}$ atoms in $\mathrm{H}_{2}$. The lifetimes of the atoms were found to be highly dependent on the nature of their surrounding media. The decay behavior suggests complex mechanisms involving several types of processes including autoignition types. Certain spectral changes were observed upon decay or annealing of the irradiated materials. Besides obtaining sharper and more resolved spectra, additional lines, usually of weak intensity, were seen. The possible interactions or species responsible for these lines are discussed.

Gas-phase radiolysis of isobutane, R. P. Borkowski and P. J. Ausloos, J. Chem. Phys. 38, No. 1, 36-44 (Jan. 1, 1963). The radiolysis of $\left(\mathrm{CH}_{3}\right)_{3} \mathrm{CD}-\mathrm{I}_{2}$ and $\left(\mathrm{CH}_{3}\right)_{3} \mathrm{CH}-\left(\mathrm{CD}_{3}\right)_{3} \mathrm{CD}-\mathrm{I}_{2}$ mixtures have been investigated as a function of pressure from $30^{\circ}$ to $225^{\circ} \mathrm{C}$. Propane, which is the major product, is mostly formed by a hydride transfer reaction such as sec$\mathrm{C}_{3} \mathrm{H}_{7}^{+}+\left(\mathrm{CH}_{3}\right)_{3} \mathrm{CH} \rightarrow \mathrm{C}_{3} \mathrm{H}_{8}+\left(\mathrm{CH}_{3}\right)_{3} \mathrm{C}^{+}$. From the distribution of the isotopic propanes produced in the radiolysis of $\left(\mathrm{CH}_{3}\right)_{3} \mathrm{CD}$ it can be concluded that hydrogen atoms in the sec-propyl ion are randomized in various degrees depending on the pressure of isobutane. Ethane is mainly formed by a hydride transfer reaction

$$
\mathrm{C}_{2} \mathrm{H}_{5}^{+}+\left(\mathrm{CH}_{3}\right)_{3} \mathrm{CH} \rightarrow \mathrm{C}_{2} \mathrm{H}_{6}+\mathrm{C}_{4} \mathrm{H}_{3}^{+}
$$


Two distinct processes lead to the formation of ethylene, (a) molecular elimination from isobutane and (b) reaction of vinyl ions with isobutane. The effect of zenon krypton and argon on the product distribution and the randomization of the sec-propyl ion is discussed in some detail.

Comparative measurements on polystyrene with three different equilibrium ultracentrifuges, D. McIntyre, L. C. Williams, P. E. Haxner, H. G. Kim, F. N. Weber, R. F Bunting, and D. W. Kurke, J. Polymer Sci. 62, No. 174, S136-S140 (Dec. 1962).

A magnetically suspended equilibrium centrifuge of new design was compared with two other equilibrium ultracentrifuges in the determination of the molecular weight of a synthetic polymer. The speed control and optics of the magnetically suspended centrifuge allow a very precise determination of weight-average molecular weight although the $z$-average molecular weight is not in agreement with fractionation results.

Some stochastic processes in polymer systems, J. Mazur, J. Chem. Phys. 38, No. 1, 193-201 (Jan. 1, 1963).

Certain distributional problems involving polymer configurations can be treated as special classes of stochastic processes known as regenerative processes. These processes have the property that the interval (of time or of length) between two consecutive events is a random variable. The method of regeneration point is applied to the problem of random crystallization of polymers and to the problem of forcelength relationships in a one-dimensional simulation of a polymer network. By assuming that the events of randomly placing crystalline units on a polymer chain are statistically independent, and that the probability of the first event occurring in a given interval is a simple step function, the direct application of the method of regeneration point leads to a well-known equation from the theory of molecular distribution in one-dimensional hard-core fluids. In the second problem it is assumed that a single polymer chain consists of mesh points connected by flexible chains. A restriction is imposed that these mesh points cannot pass through each other. The molecular distribution functions for these mesh points are derived with the help of the regeneration-point process. By applying this method, the relationships of the network extension to the fixed force are derived. It is also found that the affine transformation rule for the force-biased distribution of chain lengths holds strictly only if the array represents a Poisson distribution of mesh points.

On the three-particle scattering operator in classical gases, J. Weinstock, Physics Letters 3, No. 6, 260-262 (Feb. 1, 1963).

The three-particle scattering operator is the central quantity which must be calculated in order to determine the density dependence of transport coefficients in gases. A perturbation method is presented, for such a calculation, which is based upon the "binary collision expansion" of the "Greens function" form of the three-particle scattering operator. In addition, it is pointed out that the $n$-particle scattering operators of non-equilibrium statistical mechanics are actually the asymptotic forms of more general time dependent $n$ particle operators, and that a complete description of nonequilibrium phenomena may be obtained from a knowledge of the time dependence of these more general operators.

Rotational, vibrational, and electronic energy transfer in the fluorescence of nitric oxide, H. P. Broida and T. Carrington, J. Chem. Phys. 38, No. 1, 136-147 (Jan. 1, 1963). A sharp emission line of ionized cadmium from an electric discharge excites NO molecules to the $K^{\prime}=13$ rotational level of the $\nu^{\prime}=1$ vibrational level of the $A^{2} \Sigma^{+}$electronic state. Steady-state fluorescence has been observed from this level and from neighboring levels populated by collisional interaction between the excited and added inert molecules. Cross sections have been measured in $\mathrm{He}, \mathrm{Ar}, \mathrm{H}_{2}, \mathrm{~N}_{2}, \mathrm{NO}$, and $\mathrm{CO}_{2}$ for electronic deactivation to the ground $X^{2}$ II state, for vibrational deactivation to the $v^{\prime}=0$ level of the $A^{2} \Sigma^{+}$state, and for rotational exchange in the $A^{2} \Sigma^{+}$state. It has been established that rotational transitions having changes in rotational quantum number greater than unity take flace with high probability, contrary to the optical selection rule.
Observations of synchrotron radio noise at the magnetic equator following the high altitude nuclear explosion of July 9, 1962, G. R. Ochs, D. T. Farley, Jr., K. L. Bowles, and P. Bandyopadhay, J. Geophys. Res. 68, Y01-711 (Feb. 1963)

This paper describes the results of radio measurements made in Peru of synchrotron radiation at $30 \mathrm{Mc} / \mathrm{s}$ and $50 \mathrm{Mc} / \mathrm{s}$. This radiation was produced by relativistic electrons injected into trapped orbits in the earth's magnetic field during the high altitude nuclear explosion of July 9, 1962. A preliminary interpretation of these results is also given.

At $50 \mathrm{Mc} / \mathrm{s}$ there was a brief transient increase in the antenna temperature of $4.5 \times 10^{4}{ }^{\circ} \mathrm{K}$ shortly after the explosion. This car be compared to the normal antenna temperature at that time of $5.5 \times 10^{3}{ }^{\circ} \mathrm{K}$. The excess temperature soon decreased to about $1 \times 10^{4} \mathrm{~K}$ and has since decayed only very slowly from this value, with a time constant of about two months. From the early transient changes in the antenna temperature, a fairly accurate description of the energy distribution of the electrons is obtained. This spectrum is found to vary almost exactly as the fission spectrum, $\exp \left(-0.575 E-0.055 E^{2}\right)$, in the range $1 \leq E \leq 5$, where $E$ is the kinetic energy in Mev. Above $5 \mathrm{Mev}$ the spectrum falls off somewhat faster than this expression, but the measurements are rather poor in this range. The value $2 \times 10^{24}$ is obtained as a rough estimate of the total number of electrons with energies of the order of $1 \mathrm{Mev}$ or greater that were trapped after the explosion.

The measurement of voltage by the use of the Stark effect, Y. Beers and G. L. Strine (Intern. Conf. Precision Electromagnetic Measurements, Boulder, Colo., 1962), IRE Trans. Instr. I-II, $1 \% 1$ (Dec. 1962).

The theory of the Stark effect is reviewed with regard to its possible application of measuring voltages. It is pointed out that the effect can be used only to measure relative voltage and that the accuracy is likely to be limited by the accuracy with which the electrode separation can be determined. Therefore, the most sophisticated types of molecular frequency standards may not be required. The Stark method appears to hold a particular advantage for the measurement of high voltage since no voltage divider is required. Also, two possible methods of comparing ac voltages to de voltages are discussed. Finally, an experimental Stark voltmeter employing a millimeter wave Fabry-Perot absorption cell is discussed. Calculations concerning $J=2 \rightarrow 3$ transition of methyl cyanide at 55 Ge indicate that in principle the precision obtainable with a field strength of $10^{4}$ volts $/ \mathrm{cm}$ should be in the neighborhood of one part in a million, if field inhomogeneities can be neglected.

The sequence selection problem in the crystallization of polymers. I. Homopolymers, F. Gornick and J. L. Jackson, J. Chem. Phys. 38, No. 5, 1150-1154 (Mar. 1963).

The crystallization of linear polymer chains is considered as a process involving the selection of crystallizable sequences from the melt. If, owing to the requirements of thermodynamic stability, such sequences must exceed in length some critical value less than the chain length, and if the selection process is random, then the melt will be increasingly subdivided into uncrystallized sequences of varying length. Some of these may be expected to be less than the critical length so that the segments comprising them are "wasted" insofar as participation in further crystallization is concerned. An approximate sequence length distribution function for the uncrystallized sequences in the system is derived and utilized in connection with the problem of retardation in crystallization kinetics.

Detection of high altitude nuclear detonations using the VLF phase shift technique, A. G. Jean and D. D. Crombie, IEE Trans. Nucl. Sci. NS-10, 242-253 (Jan. 1963).

It is well known that nuclear detonations at heights of about $30 \mathrm{~km}$ or more can create large increases in the electron density of the upper atmosphere not only in the general area of the blast but also in areas remote from it. In this paper, the effects of such nuclear explosions on the lower ionosphere are considered. The influence of these ionospheric changes on the propagation of VLF signals is then discussed from the point of view of the detection of such nuclear explosions. 
Infrared spectrum of difluoramine, J. J. Comefore, D. E. Mann, L. J. Schoen, and D. R. Lide, Jr., J. Chem. Phys. 38, No. 2, 461-463 (Jan. 1963).

The infrared spectrum of gaseous difluoramine, $\mathrm{NF}_{2} \mathrm{H}$ has been investigated over the range $250-4000 \mathrm{~cm}^{-1}$. Four bands of $\mathrm{NF}_{2} \mathrm{D}$ have also been observed. The fundamental frequencies (in $\mathrm{cm}^{-1}$ ) and their species are as follows:

$\mathrm{NF}_{2} \mathrm{H}: \nu_{1}\left(\mathrm{a}^{\prime}\right): 3193 ; \nu_{2}\left(\mathrm{a}^{\prime}\right): 1307 ; \nu_{3}\left(\mathrm{a}^{\prime}\right): 972 ; \nu_{4}\left(\mathrm{a}^{\prime}\right): 500 ; \nu_{5}\left(\mathrm{a}^{\prime \prime}\right)$ : $1424 ; \nu_{6}\left(\mathrm{a}^{\prime \prime}\right): 888$

$\mathrm{NF}_{2} \mathrm{D}: \quad \nu_{1}\left(\mathrm{a}^{\prime}\right):[2333] ; \quad \nu_{2}\left(\mathrm{a}^{\prime}\right): 1008 ; \quad \nu_{3}\left(\mathrm{a}^{\prime}\right): 972 ; \quad \nu_{4}\left(\mathrm{a}^{\prime}\right):[500] ;$ $\nu_{5}\left(\mathrm{a}^{\prime \prime}\right): 1042 ; \nu_{6}\left(\mathrm{a}^{\prime \prime}\right): 888$

where the bracketed values were not observed directly. The fine structure resolved in several of the bands led to a value for $A-(B+C) / 2$ in agreement with the microwave result. No inversion splitting was detected.

Homogeneous anionic polymerization. I. Molecular weights of polystyrene initiated by sodium napthalene, M. Morton, R. Milkovich, D. MeIntyre, and J. L. Bradley, J. Polymer Sci. 1, Pt. A, 443-459 (Jan. 1963).

Studies of the anionic polymerization of styrene by sodium napthalene have shown the type of molecular weight distributions that can be obtained under suitable experimental conditions. Detailed descriptions and techniques are given for all experimental work because of their importance in the preparation of polymers having narrow molecular weight distributions. It has been found, however, that the presence of even trace quantities of impurities are sufficient to prevent the preparation of a "monodisperse" sample, and that it cannot be arbitrarily assumed that even in the same laboratory a successful reaction can always be completed.

\section{Other NBS Publications}

J. Research NBS 67B (Math. \& Math. Phys.), No. 2 (Apr.June 1963). 75 cents.

Maximum cellular Boolean functions and perfect Gray codes. A. J. Goldman and B. K. Bender.

The meaning of Betti's reciprocal theorem. C. Truesdell.

Effect of molecular weight on viscoelastic properties of polymers as predicted by a molecular theory. H. Oser and R. S. Marvin. (See above abstract).

Selected bibliography of statistical literature: supplement, 1958-1960. L. S. Deming.

\section{J. Research NBS 67D (Radio Prop.), No. 4 (July-Aug. 1963).} 70 cents.

Influence of the lower ionosphere on propagation of VLF waves to great distances. J. R. Wait.

Comments on a paper "Auroral Sporadic-E Ionization" by Robert D. Hunsucker and Leif Owren. J. M. Bullen and G. A. M. King.

Reply to J. M. Bullen and G. A. M. King's "Comments on a paper 'Auroral Sporadic- $E$ Ionization' by Robert D. Hunsucker and Leif Owren." R. D. Hunsucker and L. Owren.

Optimum reception pattern of the Beverage wave antenna at very low frequencies. E. W. Seeley.

Effect of a dissipative medium of finite size on antenna measurement. K. Iizuka and R. W. P. King.

Some implications of aircraft interference patterns in troposcatter reception. J. A. Bradshaw.

Asymptotic behavior of the current on an infinite cylindrical antenna. K. S. Kunz.

A dipole approximation of the backscattering from a conductor in a semi-infinite dissipative medium. M. B. Kraichman.

Small electric and magnetic antennas with cores of a lossy dielectric. J. Galejs.

Profiles of electron density over the magnetic equator obtained using the incoherent scatter technique, K. L. Bowles et al., NBS Tech. Note 169 (Mar. 16, 1963), 25 cents.

Lectures on ion-atom collisions, M. R. C. McDowell, NBS Tech. Note 185 (Mar. 15, 1963), 40 cents.

Transmission and reflection of electrons by aluminum foils M. J. Berger, NBS Tech. Note 187 (April 1, 1963), 15 cents.
Lasers, T. R. Lawrence, J. Wash. Acad. Sci. 53, 25-34 (Feb. 1963).

Gas evolution from metal surfaces during fatigue stressing, W. L. Holshouser and J. A. Bennett, Am. Soc. Testing Mater. Preprint 62 (June 1962).

The evolution of a conference, J. M. Richardson (Intern Conf. Precision Electromagnetic Measurements, Boulder, Colo., 1962), Trans. IRE Instr. I-II, 82 (Dec. 1962).

Infrared absorption spectra of $\mathrm{B}_{2} \mathrm{O}_{3}, \mathrm{~B}_{2} \mathrm{O}_{2}$, and $\mathrm{BO}_{2}$ in solid argon matrices, A. Sommer, D. White, M. J. Linevsky, and D. E. Mann, J. Chem. Phys. 38, No. 1, 87-98 (Jan. 1963).

The collaborative test, W. J. Youden, J. Assoc. Offic. Agric Chem. 46, 55-62 (Feb. 1963).

Conductive floors, F. L. Hermach, Intern. Assoc. Elec. Inspectors News Bull., p. 40-44 (July 1962).

Ionic interactions with sugar colorant during char filtration, F. G. Carpenter, D. Larry, and V. R. Dietz, Proc. 7th Tech. Session on Bone Char 1961, p. 259 (Bone Char Research Project Inc., Charlestown, Mass. 1962).

Note on the Kubelka method of measuring water absorption of leather, R. L. Hebert and A. E. McDonell, J. Am. Leather Chemists' Assoc. LVII, No. 9, 461-469 (Sept. 1962).

Intercomparisons of laboratory test results, J. Mandel, Proc Instr. Soc. Am., Paper 44-3, 5 pages (1962).

Heat transfer between a cryo-surface and a controlled atmosphere. Part I. Experimental investigation, R. J. Richards, K. Edmonds, and R. B. Jacobs, Intern. Inst. Refrigeration, Suppl. Bull. Inst. Intern. Froid, p. 1-22 (1962).

Coatings formed on steel by cathodic protection and their evaluation by polarization measurements, W. J. Schwerdtfeger and R. J. Manuele, Corrosion 19, No. 2, 59t-68t (Feb. 1963).

Microscopy of color phenomena in polymer fracture, S. B Newman and I. Wolock, Proc. Symp. Adhesion and Cohesion, p. 218-239 (Elsevier Publ. Co., Amsterdam, The Netherlands, 1963).

Sum rules for vibrational-rotational energy levels including centrifugal distortion, H. C. Allen, Jr., and W. B. Olson, J. Chem. Phys. 37, No. 2, 212-214 (July 15, 1962).

Studies of within-the-horizon propagation at $9300 \mathrm{Mc}, \mathrm{A} . \mathrm{P}$ Barsis, A. F. Barghausen, and R. S. Kirby, IEEE Trans. Ant. Prop. AP-11, 24-38 (Jan. 1963).

Dosimetry Chemical and film media, M. Ehrlich, Book, Technology Needs for Reduction of Patient Dosage from Diagnostic Radiology, Ed. M. L. Janower, p. 81-100 (C. Thomas, Publ. Co., Springfield, Ill., 1962).

Variance of radiofrequency caused by atmospheric turbulence in line-of-sight transmissions, K. A. Norton, E. C. Barrows, M. C. Thompson, Jr., and H. B. Janes (Intern. Conf. Precision Electromagnetic Measurements, Boulder, Colo., 1962), IRE Trans. Instr. I-II, 153 (Dec. 1962).

Instrument for the continuous measurement of the density of flowing cryogenic fluids, C. E. Miller, R. B. Jacobs, and J. Macinko, Rev. Sci. Instr. 34, 24-27 (Jan. 1963).

Some problems in temperature measurements from line spectra, J. T. Jefferies, Book, Temperatures Its Measurement and Control in Science and Industry 3, Pt. 1, 703-711 (Reinhold Publ. Corp., New York, N.Y., 1962).

Direct observation of charge storage in the surface states of silicon, G. G. Harman, R. L. Raybold, and O. I. Meyer, J. Appl. Phys. 34, No. 2, 380-382 (Feb. 1963).

Confidence limits for the reliability of complex systems, J. R. Rosenblatt, Book, Statistical Theory of Reliability, Ed., M. Zelen, p. 115-148 (Univ. of Wisconsin Press, Madison, Wisc., 1963).

Third international conference on precision electromagnetic measurements, W. D. George, Nature 139, No. 4858, 921929 (Dec. 8, 1962).

Improved zinc oxide-eugenol type cements, G. M. Brauer, L. Simon, and L. Sangermano, J. Dental Res. 41, No. 5, 1096-1102 (1962).

Some early results from the ionospheric topside sounder satellite, R. W. Knecht and T. E. VanZandt, Nature 19\%, 641-644 (Feb. 16, 1963).

Decibels return loss to magnitude of voltage reflection coefficient, R. W. Beatty, Microwave Eng. Handb. and Buyer's Guide, p. TD188-TD192 (1961-62). 
Dielectric constant of $\mathrm{Cr}_{2} \mathrm{O}_{3}$ crystals, P. H. Fang and W. S. Brower, Phys. Rev. 129, No. 4, 1561 (1963)

Curves for ground wave propagation over mixed land and sea paths, J. R. Wait and L. C. Walters, IEEE Trans. Ant. Prop. AP-11, 38-45 (Jan. 1963).

Alteration of the muscovite absorption spectrum by $\mathrm{KBr}$ pellet preparation, S. Ruthberg, M. W. Barnes, and R. H. Noyce,

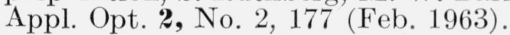

A survey of some mathematical models in the theory of reliability, G. H. Weiss, Book, Statistical Theory of Reliability, Ed. M. Zelen, p. 3-54 (University of Wisconsin Press, Madison, Wisc., 1963).

Thickness determination, V. A. Lamb, Electroplaters Process Control Handb. Ed. D. G. Foulke and F. E. Crane, Jr., Chapt. 12, p. 327-346 (Reinhold Publ. Corp., New York, N.Y., 1963).

Measurement of RF peak pulse power by a samplingcomparison method, P. A. Hudson, W. L. Hudson, W. L. Ecklund, and A. R. Ondrejka (Intern. Conf. Precision Electromagnetic Measurements, Boulder, Colo., 1962), IRE Trans. Instr. I-II, 280 (Dec. 1962)

Radiation of sound by ocean waves, R. K. Cook., Proc. 4th Intern. Congress Acoustics, Preprint 043 (Organization Committee, Copenhagen, Denmark, 1962).

Radiation effects on man, L. S. Taylor, Nucleonics 21, No. 3, 58-60 (Mar. 1963).

Identification of Ga II lines in stellar spectra, W. P. Bidelman and C. H. Corliss, Astrophys. J. 135, No. 3, 968-969 (1962).

Current trends and prospects, R. B. Stewart, R. V. Smith, and T. R. Strobridge, Cryogenics 2, No. 6, 321-324 (Dec. 1962).

Hyperfine structure in the spectrum of mercury hydride, T. L. Porter and S. P. Davis, J. Opt. Soc. Am. 53, No. 3, 338 (Mar. 1963).

Measurement and standardization of dielectric samples, H. E. Bussey and J. E. Gray (Intern. Conf. Precision Electromagnetic Measurements, Boulder, Colo., 1962), IRE Trans. Instr. I-II, 162 (Dec. 1962).

Primary processes in the photochemical decomposition of nitroalkanes, R. E. Rebbert and N. Slagg, Bull. Soc. Chim. Belges 71, 709-721 (1962).

Polysulfide sealants, pt. II. Service properties, D. A. George, F. Roth, and P. Stone, Adhesives Age 6, 35ff (Mar. 1963).

Plating specifications, F. Ogburn, Electroplaters Process Control Handb. Ed. D. G. Foulke and F. E. Crane, Jr., chapt 17, p. 406-407 (Reinhold Publ. Corp., New York, N.Y., 1963).

Spectrum analysis of extremely low frequency variations of quartz oscillators, W. R. Atkinson, L. Fey, and J. Newman, IEEE Trans. Ant. Proc. 51, 379 (Feb. 1963).

A note on $E$-field and $H$-field losses for gound-based antennas, J.R. Wait, IEEE Trans. Ant. Proc. 51, 366 (Feb. 1963).

Improved sample holder for X-ray diffractometer furnace, E. M. Levin and F. A. Mauer, J. Am. Ceram. Soc. 46, No. 1, 59-60 (Jan. 1963).

Fluorescence of teeth, A. F. Forziati and M. P. Kumpula, Frontiers of Dental Sci., p. 106-112 (Natl. Sci. Teachers Assoc., Washington, D.C., Dec. 1962).

A note on diurnal phase changes of very-low-frequency waves for long paths, J. R. Wait, J. Geophys. Res. 68, No. 1, 338-340 (Jan. 1, 1963).

Helium, V. Arp and R. H. Kropschot, Book, Applied Cryogenic Engineering, Ed. R. W. Vance, chapt. 12, 321-343 (John Wiley \& Sons, Inc., New York, N.Y., 1962).

Pitfalls in determinations of the compressive strength of concrete, J. R. Dise, Mod. Concrete 26, No. 3, 48-51 (July 1962).

Determination of lead in leaded steels by X-ray spectroscopy, B. A. Kilday and R. E. Michaelis, Appl. Spectry. 16, No. 4, 136-138 (1962).

Infrasonics, R. K. Cook, McGraw-Hill Yearbook of Science \& Technology, p. 275-276 (1962).

The aurora and trapped electrons, F. E. Roach, J. Geophys. Res. 68, 1015-1021 (Feb. 15, 1963).

Behavior of revivified char in storage, J. Redd and F. G. Carpenter, Proc. 7th Tech. Session on Bone Char 1961, p. 223 (Bone Char Research Project, Inc., Charlestown, Mass., 1962).
A method for determining the height and geographical position of an auroral are from one observing station, M. H. Rees, J. Geophys. Res. 68, No. 1, 175-183 (Jan. 1, 1963).

A high-latitude investigation of the natural very-low-frequeney electromagnetic radiation known as chorus, J. $\mathrm{H}$. Pope, J. Geophys. Res. 68, No. 1, 83-99 (Jan. 1, 1963).

The reactions of methyl radicals with aromatic compounds. I. Toluene, ethylbenzene, and cumene, I. B. Burkley and R. E. Rebbert, J. Phys. Chem. 6\%, No. 1, 168-169 (Jan. 1963).

A comparison of direct and servo methods for utilizing cesium beam resonators as frequency standards, R. E. Beehler, W. R. Atkinson, L. E. Heim, and C. S. Snider (Intern. Conf. Precision Electromagnetic Measurements, Boulder, Colo., 1962), IRE Trans. Instr. I-II, 231 (Dec. 1962). Image-gloss test; Apparatus and procedure, W. N. Harrison, Proc. Porcelain Enamel Inst. Forum 23, 154-163 (1962).

Safety levels in military inventory management, F. L. Alt, Operations Res. 10, No. 6, 786-794 (Dec. 1962).

Size-dependent spin lattice relaxation time, P. H. Fang, Phys. Rev. 129, No. 4, 1548-1549 (1963).

Mathematical services for standards laboratories, A. T McPherson, Rev. Math Fisica Teorica, XIV, Series A, Publ. 861, Nos. $1 \&$ 2, 277-285 (Univ. Nacional de Tucuman, Argentina, 1962).

Artificial heating of the electrons in the $F$ region of the ionosphere, D. T. Farley, Jr., J. Geophys. Res. 68, No. 2 401-413 (Jan. 15, 1963).

Cryogenic impurity adsorption from hydrogen, M. J. Hiza, Chem. Eng. Progr. 56, 68-71 (Oct. 1960).

Shear strength of beams without web reinforcement containing deformed bars of different yield strengths, R. G. Mathey and D. Watstein, J. Am. Concrete Inst. 60, No. 2, 183-207 (Feb. 1963).

Corrosion resistance, G. A. Ellinger, Welding Handbook, 5th Ed. p. 6.1-6.72 (American Welding Society, New York, N.Y., 1963).

Cryogenic testing of structural solids, R. M. McClintock, Eng. Quart. 2, No. 1, 28-35 (Feb. 1962).

Thermometric cells for calibration of liquid-in-glass thermometers, D. P. Enagonio, Book, Temperature, Its Measurement and Control in Science and Industry $\mathbf{3}, \mathrm{Pt}$. 2, 219-230 (Reinhold Pub. Corp., New York, N.Y., 1962).

Roger Joseph Boscovich and the combination of observations, C. Eisenhart, Actes Symp. Intern. R. J. Boskovic 1961, p. $19-25$ (1962).

Tentative U.S. standard for colors of signal lights, F. C. Brechenridge, Illum. Eng. 57, 575-576 (Sept. 1962).

Comment of empirical inference of Doppler widths, R. N Thomas, Astrophys. J. 137, No. 1, 38-40 (Jan. 1963).

Uncertainties in calibrations, W. J. Youden, IRE Trans. Instr. I-II, Nos. 3 \& 4, 133-138 (Dec. 1962).

Reaction of oxygen with unkilned bone char at low temperatures $\left(<300^{\circ} \mathrm{C}\right)$, F. G. Carpenter and V. R. Dietz, Proc. 7th Tech. Session on Bone Char 1961, p. 237 (Bone Char Research Project Inc., Charlestown, Mass., 1962).

Horizons in dentistry, G. C. Paffenbarger, Frontiers of Dental Sci., p. 122-128 (Natl. Sci. Teachers Assoc., Washington, D.C., Dec. 1962).

Experimental determination of the frequency ratio of optical harmonics, H. S. Boyne and W. C. Martin, J. Opt. Soc. Am. 52, No. 8, 880-884 (Aug. 1962).

The reactions of methyl radicals with aromatic compounds. II. The xylenes, W. A. Saunders and R. E. Rebbert, J. Phys. Chem. 67, No. 1, 170-171 (Jan. 1963).

Desorption of calcium and sulfate ions from revivified bone char, H. M. Rootare, V. R. Dietz, and F. G. Carpenter, Proc. 7th Tech. Session on Bone Char, 1961, p. 293 (Bone Char Research Project Inc., Charlestown, Mass., 1962).

Energy use and power demands in all-electric houses equipped with air-to-air heat pumps, J. C. Davis and P. R. Achenbach, ASHRAE J. 4, No. 9, 87-95 (Sept. 1962).

Ferroelectric switching and the Sievert integral, P. H. Fang and I. R. Stegun, J. Appl. Phys. 34, No. 2, 284-286 (1963).

The conjugacy of magnetic disturbance variations, G. M. Boyd, J. Geophys. Res. 68, No. 4, 1011-1013 (Feb. 13, 1963). 
The giant resonance of the nuclear photoeffect, E. G. Fuller and E. Hayward, Book, Nuclear Reactions II, pp. 113-194 (North-Holland Publ. Co., Amsterdam, The Netherlands, 1962).

Comparison of the rubidium-87 and proton Zeeman transition frequencies in the earth's magnetic field, P. L. Bender, Phys. Rev. 128, No. 5, 2218-2221 (Dec. 1962).

Precision millimeter wave interferometry at the U.S. National Bureau of Standards, W. Culshaw, J. M. Richardson, and D. M. Kerns, Interferometry Symp., June 9-11, 1959, paper 4-3, p. 331 (National Physical Laboratory, Teddington, Middlesex, England, 1960).

Mechanical properties of materials, R. H. Kropschot, Book, Applied Cryogenic Engineering, Ed. R. W. Vance and W. M. Duke, 44-59 (John Wiley \& Sons, Inc., New York, N.Y., 1962).

A sing-around velocimeter for measuring the speed of sound in the sea, M. Greenspan and C. E. Tschiegg, Book, Underwater Acoustics, Lecture 5, p. 87-101, (Plenum Press, Inc., New York, N.Y., 1962).

Relative signs of proton spin-spin coupling constants, E. Lustig, J. Chem. Phys. 37, No. 11, 2725-2726 (Dec. 1962).

Quantitative metallographic evaluations of graphitic microstructures, L. L. Wyman and G. A. Moore, Mod. Castings 43, No. 1, 7-16 (Jan. 1963).

A possible effect of lower atmospheric divergence on the local electron density in the ionosphere, N.J. Macdonald and R. W. Knecht, Inst. Solar Terrestrial Res. Tech. Report 8 (High Altitude Observatory, University of Colorado, Boulder, Colo,, 1960).

On the realistic measurement of precision and accuracy, C. Eisenhart, ISA Proc. Eighth Natl. Aero-Space Instrumentation Symp., Washington, D.C., p. 75-83 (May 1962).

Interpolation of platinum resistance thermometers, $10^{\circ}$ to $273.15^{\circ} \mathrm{K}$, R. J. Corruccini, Book, Temperature, Its Measurement and Control in Science and Industry 3, Pt. 1, 329-338 (Reinhold Publ. Corp., New York, N.Y., 1962).

Polysulfide sealants: Part I. Formulation and application properties, D. A. George, L. Dunlap, and P. Stone, Adhesives Age 6, No. 2, 32-36 (Feb. 1963).

Studies of errors in economic statistics, D. Rosenblatt, 1962 Proc. Business and Economic Statistics Section, Am. Stat. Assoc., p. 217 (1962).

Low temperature insultation, R. H. Kropschot, Book, Applied Cryogenic Engineering, Ed. R. W. Vance and W. M. Duke, p. 152-169 (John Wiley \& Sons, Inc., New York, N.Y., 1962).

Communications in electronics, J. Stern, Signal 16, No. 10, 78-79 (June 1962).

Theory of the deep penetration of electrons and charged particles, L. V. Spencer and J. Coyne, Phys. Rev. 128, No. 5, 2230-2237 (Dec. 1962).

Quantities and units for dosimetry in diagnostic radiology, H. O. Wyckoff (Symp. under the auspices of the Division of Radiological Health, U.S. Public Health Service, Wash., D.C., March 5-6, 1962), Book, Technological Needs for Reduction of Patient Dosage from Diagnostic
Radiology, Ed. M. L. Janower, p. 5-9 (Charles C. Thomas, Publ., Springfield, Ill., 1963).

Precision of methods for measuring tensile strength, stretch, and tensile energy absorption of paper, T. W. Lashof, Tappi 46, No. 1, 52-59 (Jan. 1963).

Dimensional changes in dentures, G. C. Paffenbarger, J. B Woelfel, and W. T. Sweeney, Dental Practitioner 13, No. 2, 64-69 (Oct. 1962).

Current trends and prospects in cryogenics, R. W. Stewart, R. V. Smith and T. R. Strobridge, Cryogenies 2, No. 6, 321-324 (Dec. 1962).

Tunneling between a normal metal and a superconductor, J. Harden and R. S. Collier, Cryogenies 2, No. 6, 369-370 (Dec. 1962).

Comments on the Rosen interaction potential of two helium atoms, B. M. Axilrod, J. Chem. Phys. 38, No. 1, 275-277 (Jan. 1963).

Effective impedance of a wire grid parallel to the earth's surface, J. R. Wait, IRE Trans. Ant. Prop. AP-10, No. 5 , 538-542 (Sept. 1962).

Dislocations and chemical etch pits in copper, A. W. Ruff, Jr., J. Appl. Phys. 33, No. 12, 3392-3400 (Dec. 1962).

The intensity and spectral distribution of scattered radiation from Co ${ }^{60}$ sources, B. Petree and J. C. Humphreys, Radiology 80, No. 1, 120 (Jan. 1963).

Performance characteristics of turbine flowmeters, M. R. Shafer, J. Basic Eng. 84, Series D, No. 4, 471-485 (Dec. 1962).

Experimental $g f$-values for seventy elements, C. H. Corliss, Astrophys. J. 136, No. 3, 916-934 (Nov. 1962).

Scientific information activities at the National Bureau of Standards, W. R. Tilley (53rd Special Libraries Assoc. Conv., Metals Division, May 29, 1962, Washington, D.C.) Spec. Lib. p. 29-34 (Jan. 1963).

Properties of a silica-reinforced polymer for dental restorations, R. L. Bowen, J. Am. Dental Assoc. 66, No. 1, 57-64 (Jan. 1963).

Mechanical basis of diffusion, C. Truesdell, J. Chem. Phys. 37, No. 10, 2336-2344 (Nov. 1962).

Current status of the statistical theory of mass spectra, H. M. Rosenstock and M. Krauss, Book, Advances in Mass Spectrometry 2, 251-284 (Pergamon Press, London, England, 1962).

Available heat sinks for protected underground installations, B. A. Peavy, Proc. Natl. Acad. Sci.-Natl. Res. Council Meeting on Environmental Engineering in Protective Shelters, p. 237-248 (Feb. 1960).

The sudden ionospheric disturbance, C. S. Warwick, Book, Radio Astronomical and Satellite Studies of the Atmosphere, p. 457-475 (North-Holland Publ. Co., Amsterdam, The Netherlands, 1963).

Realistic estimates of error, W. J. Youden, J. Instr. Soc. Am. 8, No. 10, 57-58 (Oct. 1962).

*Publications for which a price is indicated are available from the Superintendent of Documents, U.S. Government Printing Office, Washington, D.C., 20402 (foreign postage one-fourth additional). Reprints from outside journals and the NBS Journal of Research may often be obtained directly from the authors. 